\title{
Pengaruh Latihan Ladder Drill Terhadap Kelincahan Dan Kecepatan Pemain Futsal Undikma
}

\author{
${ }^{1}$ Fadli Zainuddin, ${ }^{2} \mathbf{P}$. Muhammad Yusuf \\ Fakultas Ilmu Keolahragaan dan Kesehatan Masyarakat, Universitas \\ Pendidikan Mandalika Mataram \\ Email: pmyusufundikma@gmail.com
}

\begin{abstract}
Abstrak. Futsal adalah permainan jenis sepakbola yang dimainkan oleh 10 orang (masingmasing 5 orang), serta menggunakan bola lebih kecil dan lebih berat daripada yang digunakan dalam sepakbola. Futsal adalah permainan yang sangat cepat dan dinamis, karena dari segi lapangan yang relatif kecil hampir tidak ada ruang untuk membuat kesalahan. Oleh karena itu setiap pemain futsal dituntut memiliki kondisi fisik yang prima. Salah kondisi fisik yang dominan dalam cabang olahraga futsal adalah kecepatan dan kelincahan. Latihan ladderi drill merupakan cara terbaik untuk meningkatkan kecepatan, kelincahan, koordinasi dan keseimbangan secara keseluruhan dan latihan ini tidak dimaksudkan untuk mengalami kelelahan berarti atau mengalami sesak nafas. Salah satu permasalahan dalam tim futsal Undikma adalah belum merata kecepatan dan kelincahan para pemain dalam latihan maupun dalam pertandingan, oleh karena itu untuk memecahkan masalah tersebut penulis akan menerapkan bentuk latihan yaitu Pengaruh Latihan Ladder Drill Terhadap Kelincahan dan Kecepatan Pemain Futsal Undikma. Tujuan dari penelitian ini adalah mengukur peranan latihan ladder drill dalam meningkatkan kelincahan dan kecepatan pemain futsal Undikma. Dari data hasil penelitian menunjukan bahwa latihan ladder drill dapat meningkatkan kelincahan dan kecepatan pemain futsal Undikma. Hasil tes kelincahan nilai t-hitung $(4,75)>$ dari t-tabel (1,812), dengan dengan demikian hipotesis nihil (Ho) ditolak dan hipotesis alternatif $(\mathrm{Ha}$ ) diterima, berdasarkan nilai rata-rata dari pretest sebesar 186 dan posttest sebesar 173,6 maka terdapat peningkatan hasil dari latihan yang dilakukan selama pertemuan sesuai dengan program latihan yang direncanakan menghasilkan nilai rata-rata sebesar 12,4. Sedangkan hasil tes kecepatan nilai t-hitung $(15,48)>$ dari t-tabel $(1,812)$ dengan dengan demikian hipotesis nihil $(\mathrm{Ho})$ ditolak dan hipotesis alternatif $(\mathrm{Ha})$ diterima, berdasarkan nilai rata-rata dari pretest sebesar 40,1 dan posttest sebesar 25,7 maka terdapat peningkatan hasil dari latihan yang dilakukan selama pertemuan sesuai dengan program latihan yang direncanakan menghasilkan nilai rata-rata sebesar 14,4.
\end{abstract}

Kata Kunci : Kelincahan, Kecepatan,Futsal.

Abstrack. Futsal is a type of football game played by 10 people (5 people each), and uses a ball smaller and heavier than that used in football. Futsal is a very fast and dynamic game, because in terms of a relatively small field there is almost no room for mistakes. Therefore, every futsal player is required to have excellent physical condition. One of the dominant physical conditions in futsal is speed and agility. Ladderi drills are an excellent way to increase overall speed, agility, coordination and balance and they are not meant for experiencing significant fatigue or experiencing shortness of breath. One of the problems in the Undikma futsal team is the uneven speed and agility of the players in training and in matches, therefore to solve this problem the author will apply a form of training, namely the Effect of Ladder Drill Training on the Agility and Speed of Undikma Futsal Players. The purpose of this study was to measure the role of ladder drill training in increasing the agility and speed of Undikma futsal players. From the research data, it shows that ladder drill training can increase the agility and speed of Undikma futsal players. The results of the agility test of the t-value (4.75)> from the t-table $(1,812)$, thus the null hypothesis (Ho) is rejected and the alternative hypothesis $(\mathrm{Ha})$ is accepted, based on the average value of the pretest of 186 and the posttest of 186 173.6, then there is an increase in the results of the exercises 
carried out during the meeting in accordance with the planned training program resulting in an average value of 12.4. While the results of the speed test $t$-value $(15.48)>t$-table $(1,812)$, thus the null hypothesis ( $\mathrm{Ho})$ is rejected and the alternative hypothesis ( $\mathrm{Ha}$ ) is accepted, based on the average value of the pretest of 40.1 and posttest of 25.7, so there is an increase in the results of the exercises carried out during the meeting in accordance with the planned training program resulting in an average value of 14.4 .

Keywords: Agility, Speed, Futsal.

\section{PENDAHULUAN}

Olahraga yang sangat memasyarakat dan sangat populer saat ini adalah futsal. Yudianto (2009:54), futsal adalah permainan jenis sepakbola yang dimainkan oleh 10 orang (masing-masing 5 orang), serta menggunakan bola lebih kecil dan lebih berat daripada yang digunakan dalam sepakbola. Gawang yang digunakan dalam futsal juga lebih kecil. Futsal adalah permainan yang sangat cepat dan dinamis, karena dari segi lapangan yang relatif kecil hampir tidak ada ruang untuk membuat kesalahan. Bola bergulir di semua sisi lapangan permainan begitu cepat. Oleh karena itu setiap pemain futsal dituntut memiliki kondisi fisik yang prima. Kondisi fisik yang prima sangatlah menunjang penampilan seorang pemain. Kondisi fisik yang buruk tentunya akan berdampak buruk juga bagi penampilan teknik dan taktiknya.

Salah kondisi fisik yang dominan dalam cabang olahraga futsal adalah kecepatan dan kelincahan. kecepatan anggota tubuh seperti lengan atau tungkai adalah penting pula guna memberikan akselerasi kepada objek-objek eksternal seperti sepakbola, futsal, tenis lapangan, lempar cakram, bola voli, dan sebagainya. Kecepatan tergantung dari beberapa faktor yang mempengaruhinya, yaitu strength, waktu reaksi, dan fleksibilitas (Harsono 1988: 216). Menurut Nala (1998 : 74) kelincahan/agility adalah kemampuan untuk mengubah posisi tubuh, arah gerakan tubuh dengan cepat ketika sedang bergerak cepat, tanpa kehilangan keseimbangan atau kesadaran orientasi terhadap posisi tubuh.

Untuk meningkatkan kelincahan dan kecepatan dalam bermain futsal dibutuhkan bentuk latihan yang cocok agar dapat meningkat dengan baik, bentuk latihan yang cocok yaitu latihan ladder drill. Latihan ladderi drill merupakan cara terbaik untuk meningkatkan kecepatan, kelincahan, koordinasi dan keseimbangan secara seluruhan dan latihan ini tidak dimaksudkan untuk mengalami kelelahan

berarti atau mengalami sesak nafas. (Rajendra, 2016)

Salah satu permasalahan dalam tim futsal Undikma adalah belum merata kelincahan dan kecepatan para pemain dalam latihan maupun dalam pertandingan, oleh karena itu untuk memecahkan masalah tersebut penulis akan menerapkan bentuk latihan yaitu Pengaruh Latihan Ladder Drill Terhadap Kelincahan dan Kecepatan Pemain Futsal Undikma.

\section{KAJIAN LITERATUR}

Pengaruh adalah "daya yang ada atau timbul dari sesuatu (orang atau benda) yang ikut membentuk watak kepercayaan dan perbuatan seseorang" (Depdikbud,2001:845)

Menurut Sukadiyanto3 (2005:1)

menerangkan bahwa pada prinsipnya latihan merupakan suatu proses perubahan ke arah yang lebih baik, yaitu untuk meningkatkan kualitas fisik kemampuan fungsional peralatan tubuh dan kualitas psikis anak latih.

Latihan ladder drill adalah metode latihan yang berguna untuk meningkatkan kecepatan kaki, kelincahan, koordinasi dan kecepatan secara keseluruhan (Tsivkin, 2011 : 12).

Kelincahan adalah kemampuan seseorang untuk mengubah posisi di area tertentu. Seseorang yang mampu mengubah satu posisi yang berbeda dalam kecepatan tinggi dengan koordinasi yang baik, berarti dapat dikatakan bahwa kelincahanya cukup baik (KONI, 2000: A11). 
Kecepatan adalah kemampuan seseorang untuk mengerjakan atau melakukan gerakan berkesinambungan dalam bentuk yang sama dalam waktu yang sesingkat-singkatnya (KONI, 2000: A21).

Menurut Kurniawan (2012:104), futsal adalah permainan bola yang dimainkan oleh dua tim, yang masing-masing tim beranggotakan lima orang dengan tujuan untuk memasukkan bola ke gawang lawan, dengan manipulasi bola dan kaki.

\section{METODE PENELITIAN}

Jenis penelitian ini adalah eksperimen.

Rancangan penelitian ini menggunakan one group pre test-post test design (Maksum, 2012). Desain ini tidak ada kelompok kontrol, dan subjek tidak ditempatkan secara acak karena hanya ada satu kelompok saja. Populasi dalam peneltian ini adalah pemain futsal UNDIKMA yang berjumlah 10 orang. Penelitian ini menggunakan studi populasi.

Instrumen penelitian illinois agility test untuk mengukur kelincahan dan menggunakan 30 meter sprint test untuk mengukur kecepatan lari. Analisis data menggunakan uji t pada taraf signifikansi 5\%.

\section{HASIL PENELITIAN}

Data hasil tes kelincahan

\begin{tabular}{|c|c|c|c|c|c|}
\hline No & $\begin{array}{c}\text { Na } \\
\text { ma }\end{array}$ & Pretest & Postest & D & $\mathrm{D}^{2}$ \\
\hline 1 & $\mathrm{~A}$ & 16,7 & 15,5 & 1,2 & 1,44 \\
\hline 2 & $\mathrm{~B}$ & 18,4 & 17,2 & 1,2 & 1,44 \\
\hline 3 & $\mathrm{C}$ & 19,4 & 18,5 & 0,9 & 0,81 \\
\hline 4 & $\mathrm{D}$ & 19,9 & 18,3 & 1,6 & 2,56 \\
\hline 5 & $\mathrm{E}$ & 18,6 & 17,3 & 1,3 & 1,69 \\
\hline 6 & $\mathrm{~F}$ & 15,3 & 14,5 & 0,8 & 0,64 \\
\hline 7 & $\mathrm{G}$ & 19,9 & 18,5 & 1,4 & 1,96 \\
\hline 8 & $\mathrm{H}$ & 19,8 & 18,2 & 1,6 & 2,56 \\
\hline 9 & $\mathrm{I}$ & 17,2 & 16,3 & 0,9 & 0,81 \\
\hline 10 & $\mathrm{~J}$ & 20,8 & 19,3 & 1,5 & 2,25 \\
\hline Jumlah & 186 & 173,6 & 12,4 & 16,16 \\
\hline \multicolumn{2}{|l}{ Mean (M) } & 18,6 & 17,36 & 1,24 & 1,616 \\
\hline
\end{tabular}

$$
t=\frac{\sum D}{\sqrt{\frac{N \sum D^{2}-\left(\sum D\right)^{2}}{N-1}}}
$$

$$
\begin{aligned}
t & =\frac{12,4}{\sqrt{\frac{10(16,16)-(12,4)^{2}}{10-1}}} \\
\mathrm{t} & =\frac{12,4}{\sqrt{\frac{161,6-153,76}{10-1}}}
\end{aligned}
$$$$
\mathrm{t}=\frac{12,4}{\sqrt{\frac{7,84}{9}}}
$$

$\mathrm{t}=\frac{12,4}{\sqrt{0,87}}$

$\mathrm{t}=\frac{12,4}{2,61}$

$\mathbf{t}=\mathbf{4 , 7 5}$

$f=10-1=9$

$d(9)=4,75 \cdot \mathrm{p}>0,05$

Peningkatannya $=\frac{\mathrm{M}_{\mathrm{D}}}{\mathrm{M}_{\mathrm{pre}}} \times 100 \%$

$$
=\frac{12,4}{186} \times 100 \%=\mathbf{0 . 0 7} \%
$$

Jadi hasil nilai t-hitung $(4,75)>$ dari ttabel $(1,812)$ dengan dengan demikian hipotesis nihil (Ho) ditolak dan hipotesis alternatif (Ha) diterima.

Berdasarkan nilai rata-rata dari pretest sebesar 186 dan posttest sebesar 173,6 maka terdapat peningkatan hasil dari latihan yang dilakukan selama pertemuan sesuai dengan

\begin{tabular}{|c|c|c|c|c|c|}
\hline No & $\begin{array}{l}\text { Nam } \\
\text { a }\end{array}$ & $\begin{array}{l}\text { Prete } \\
\text { st }\end{array}$ & $\begin{array}{l}\text { Poste } \\
\text { st }\end{array}$ & $\mathrm{D}$ & $\mathrm{D}^{2}$ \\
\hline 1 & $\mathrm{~A}$ & 3,6 & 2,2 & 1,4 & 1,96 \\
\hline 2 & B & 3,4 & 2,1 & 1,3 & 1,69 \\
\hline 3 & $\mathrm{C}$ & 3,6 & 2,3 & 1,3 & 1,69 \\
\hline 4 & $\mathrm{D}$ & 4,3 & 3,1 & 1,2 & 1,44 \\
\hline 5 & $\mathrm{E}$ & 4,1 & 2,4 & 1,7 & 2,89 \\
\hline 6 & $\mathrm{~F}$ & 4,4 & 3,1 & 1,3 & 1,69 \\
\hline 7 & G & 3,6 & 2,1 & 1,5 & 2,25 \\
\hline 8 & $\mathrm{H}$ & 4,9 & 3,5 & 1,4 & 1,96 \\
\hline 9 & I & 4 & 2,4 & 1,6 & 2,56 \\
\hline 10 & $\mathrm{~J}$ & 4,2 & 2,5 & 1,7 & 2,89 \\
\hline \multicolumn{2}{|c|}{ Jumlah } & 40,1 & 25,7 & 14,4 & 21,02 \\
\hline \multicolumn{2}{|c|}{ Mean (M) } & 4,01 & 2,57 & 1,44 & 2,102 \\
\hline
\end{tabular}
program latihan yang direncanakan menghasilkan nilai rata-rata sebesar 12,4.

Data hasil tes kecepatan

$$
t=\frac{\sum D}{\sqrt{\frac{N \sum D^{2}-\left(\sum D\right)^{2}}{N-1}}}
$$




$$
\begin{aligned}
& t=\frac{14,4}{\sqrt{\frac{10(21,02)-(14,4)^{2}}{10-1}}} \\
& \mathrm{t}=\frac{14,4}{\sqrt{\frac{210,2-207,36}{10-1}}} \\
& \mathrm{t}=\frac{14,4}{\sqrt{\frac{2,84}{9}}} \\
& \mathrm{t}=\frac{14,4}{\sqrt{0,31}} \\
& \mathrm{t}=\frac{14,4}{0,93} \\
& \mathbf{t}=\mathbf{1 5 , 4 8} \\
& f=10-1=9 \\
& \begin{array}{l}
d(9)=\mathbf{1 5}, \mathbf{4 8} \cdot \mathrm{p}>0,05 \\
\text { Peningkatannya }=\frac{\mathrm{M}_{\mathrm{D}}}{\mathrm{M}_{\mathrm{pre}}} \times 100 \%
\end{array} \\
& \quad=\frac{14,4}{40,1} \times 100 \%=\mathbf{0 . 3 5} \%
\end{aligned}
$$

Jadi hasil nilai t-hitung $(15,48)>$ dari t-tabel $(1,812)$ dengan dengan demikian hipotesis nihil (Ho) ditolak dan hipotesis alternatif $(\mathrm{Ha})$ diterima.

Berdasarkan nilai rata-rata dari pretest sebesar 40,1 dan posttest sebesar 25,7 maka terdapat peningkatan hasil dari latihan yang dilakukan selama pertemuan sesuai dengan program latihan yang direncanakan menghasilkan nilai rata-rata sebesar 14,4.

\section{PEMBAHASAN}

Futsal adalah permainan yang sangat cepat dan dinamis, karena dari segi lapangan yang relatif kecil hampir tidak ada ruang untuk membuat kesalahan. Salah kondisi fisik yang dominan dalam cabang olahraga futsal adalah kecepatan dan kelincahan.

Untuk meningkatkan kelincahan dan kecepatan dala bermain futsal dibutuhkan bentuk latihan yang cocok agar dapat meningkat dengan baik, bentuk latihan yang cocok yaitu latihan ladder drill.

Dari data hasil penelitian menunjukan bahwa latihan ladder drill dapat meningkatkan kelincahan dan kecepatan pemain futsal Undikma. dengan rata rata peningkatan pretest dan postest sebesasar 12,4 di kelincahan dan kecepatan rata rata peningkatannya sebesar 14,4 .
Dari hasil analisis data menunjukkan adanya pengaruh signifikan dari latihan ladder drill terhadap kelicahan dan kecepatan pemian futsal Undikma. Oleh karena itu perlunya latihan yang kontinyu dan program latihan yang terstruktur perlu dijadikan sebagai acuan, agar tetap dapat terus meningkatkan kelincahan dan kecepatan para pemain di level tertinggi.

\section{SARAN}

Agar kedepannya pelatih dan pemain bisa menerapkan program latihan ladder drill dan memberikan variasi latihan agar tidak terkesan monoton, sehingga para pemain tidak jenuh dengan program latihan yang diterapkan oleh pelatih.

\section{DAFTAR PUSTAKA}

Depdikbud, 2001 hal. 845 Pengertian Pengaruh.

Harsono. (1988). Panduan Kepelatihan. Jakarta: KONI.

Komite Nasional Indonesia. 2000. Gerakan Nasional Garuda Emas. Jakarta.

Kurniawan, Feri. 2012. Buku Pintar Pengetahuan Olahraga. Jakarta: Laskar Aksara.

Maksum, Ali. 2012. Metodologi Penelitian dalam Olahraga. Surabaya : Unesa University Press.

Nala, Ngurah. 1998. Prinsip Pepelatihan Fisik Olahraga. Denpasar: PPs Universitas Udayana.

Rajendran, K. (2016). Effect of Ladder Training on Agility among College level Football Players. International Journal of Recent Research and Applied Studies. Volume 3, Issue 4 (23).

Sukadiyanto. 2005. Pengantar Teori dan Metodologi Melatih Fisik. Yogyakarta: FIK Uiversitas Negeri Yogyakarta.

Tsivkin, Troman 2011, tersedia pada http://www.sport-fitnesadvisor.com. Diunduh tanggal 2 Maret 2021.

\section{KESIMPULAN}


Jurnal Ilmiah Mandala Education

Terakreditasi Peringkat 4 (No. SK: 36/E/KPT/2019)

Yudianto, Lukman. 2009. Teknik Bermain

Sepak Bola dan Futsal.

Bandung: Visi 7. 